\title{
LA-UR-20-28275
}

Approved for public release; distribution is unlimited.

Title: Celebrating Native American Heritage Month: Area's earliest inhabitants become valuable part of Lab workforce

Author(s): $\quad$ Whitacre, Madeline Helene

Belotti, Amylee

Intended for: $\quad$ External lab comms

Issued: 
Disclaimer:

Los Alamos National Laboratory, an affirmative action/equal opportunity employer, is operated by Triad National Security, LLC for the National Nuclear Security Administration of U.S. Department of Energy under contract 89233218CNA000001. By approving this article, the publisher recognizes that the U.S. Government retains nonexclusive, royalty-free license to publish or reproduce the published form of this contribution, or to allow others to do so, for U.S. Government purposes. Los Alamos National Laboratory requests that the publisher identify this article as work performed under the auspices of the U.S. Department of Energy. Los Alamos National Laboratory strongly supports academic freedom and a researcher's right to publish; as an institution, however, the Laboratory does not endorse the viewpoint of a publication or guarantee its technical correctness. 


\section{Celebrating Native American Heritage Month: Area's earliest inhabitants become valuable part of Lab workforce}

By Madeline Whitacre and Amy Belotti, National Security Research Center archivist-historians

Sidebar:

Our area's history

Today, the Pajarito Plateau is home to Los Alamos National Laboratory and the communities of Los Alamos and White Rock. However, the area was first inhabited by Native Americans. The archeological record on the plateau dates back to the Paleoindian period, about 12,000 years ago.

The Ancestral Pueblo people (a prehistoric Native American civilization that existed from approximately 100 to 1600 C.E.) are generally considered by archeologists to be the earliest group that is clearly linked to modern Pueblos. During this period, four main communities were established:

- Tsankawi, which means "the village between two canyons at the clump of sharp round cacti,"

- Tsirege, which means "bird place,"

- Navawi, which means "from the garden" and

- Otowi, which means "gap where the water sinks".

The communities on the Pajarito Plateau were eventually abandoned during the 1500 s due to drought. However, they were temporarily reoccupied during the Pueblo Revolt of 1680 by refugees fleeing the Spanish. The archeological remains of these sites can still be seen today. 


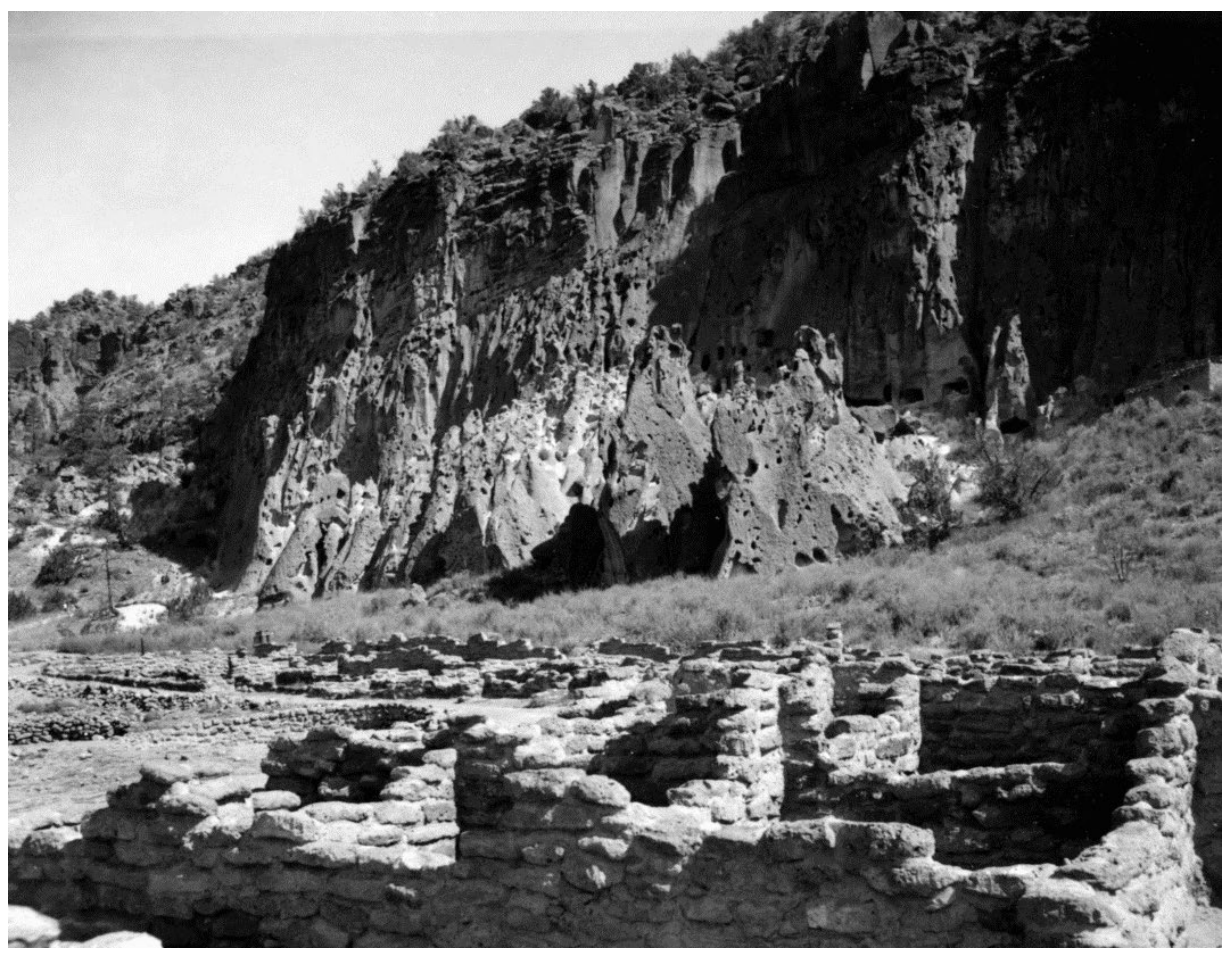

caption: The Tsankawi Pueblo, shown here in the late 1950s, is one of the pueblos near Los Alamos National Laboratory.

\section{Main story:}

By the time the then-secret laboratory was established in Los Alamos in 1943, the nearby pueblos we know today were well-established communities.

To complete its wartime mission to build the world's first nuclear weapons, the Laboratory needed many workers for all aspects of the project. As such, many Native Americans were hired to work at the Lab in various roles, such as technicians, researchers, machinists, and support staff.

By the end of the Manhattan Project in 1945, shortly after the end of World War II, many friendships had been forged between employees from the pueblos and other workers at Los Alamos. This was evidenced by gatherings, such as a post-war celebration at the San Ildefonso Pueblo, as well as individual relationships between Lab staff and pueblo residents.

Meanwhile, pueblo residents remained on as valuable members of the post-war Lab staff with additional workers hired as well.

In honor of November's Native American Heritage Month, staff at the National Security Research Center are taking a look back to LANL's early workforce and the contributions -- both to our mission and our cultural enrichment -- made by Native Americans. 


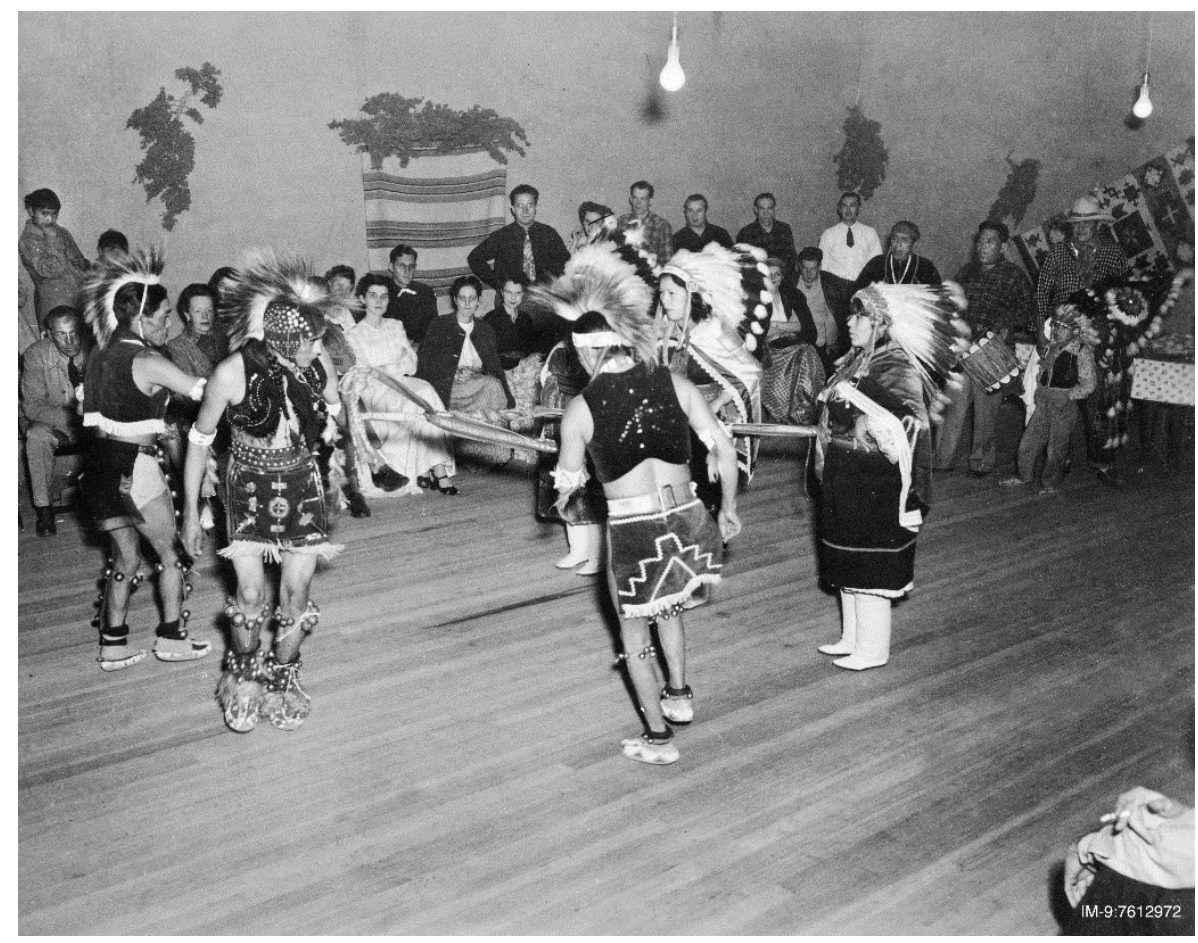

caption: After World War II ended in 1945, San Ildefonso Pueblo hosted a celebration and invited Los Alamos Lab staff to attend. This photo, and many others showing the Native American influence on the Lab, are part of the collections in the National Security Research Center -- the Lab's classified library located in the National Security Sciences Building.

\section{Floy Agnes Lee}

When Floy Agnes (Naranjo Stroud) Lee wasn't working as a blood technician at the war-time Los Alamos Lab, she played tennis.

Her regular opponent, whom she nearly always beat, was Enrico Fermi -- though she didn't know the Nobel Prize-winning physicist was someone other than just another Lab employee. 
It was this tennis partner who encouraged Lee to pursue a degree in science. Not long after WWII ended, Lee left Los Alamos for the University of Chicago, where she earned her Ph.D. in zoology. In time, she eventually made her way back to her home state.

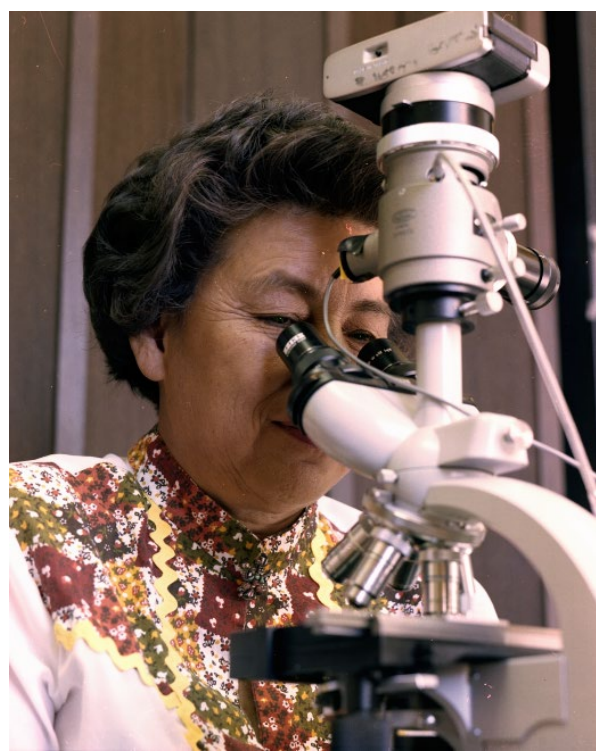

caption: Floy Agnes (Naranjo Stroud) Lee worked as a blood technician at the Lab during World War II. She went on to earn her Ph.D. at the University of Chicago and then returned to the Lab in the 1970s, where she worked until her retirement.

Lee grew up at the now-closed Albuquerque Indian School, where her parents both taught. Lee's father was from the Santa Clara Pueblo and she visited the Pueblo often. She studied biology at the University of New Mexico and was recruited to the Los Alamos Lab in 1945 to work in hematology. Lee was the technician who drew and analyzed blood from scientists Louis Slotin and Alvin Graves following the infamous accident in 1946 in which Slotin accidently created a fission reaction and died nine days later from the radiation exposure.

After completing her studies in Chicago, Lee worked as a senior scientist at the Jet Propulsion Lab in Pasadena, California. Lee returned to Los Alamos to work for the Health Research Laboratory in the 1970s. She also was a founding member of the American Indian Science and Engineering Society as well as other science groups.

Lee continued to live in New Mexico until her death in 2018 at age 95.

\section{Popovi Da}

caption: Popovi Da worked at the then-secret Lab during the Manhattan Project era, when Los Alamos staff worked to create the world's first atomic bombs that helped end World War II. Da was a machinist, artist and friend. Stories of Native Americans who were a part of the Lab's first workforce are part of the collections in the National Security Research Center, the Lab's classified library. 


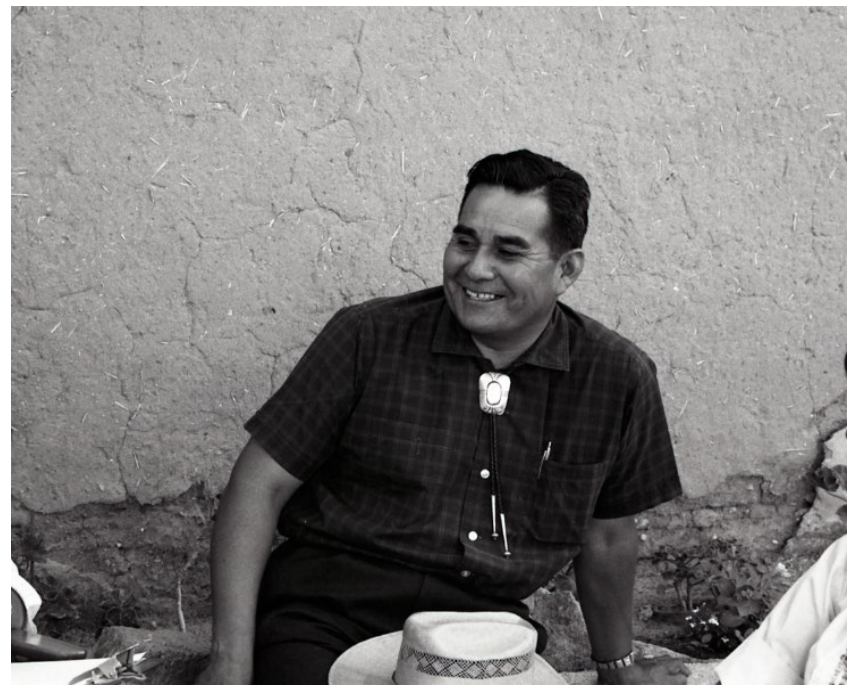

Popovi Da worked as a machinist at the Los Alamos Lab during World War II, but may be better remembered for his art and his friendship.

Da (Red Fox), who changed his name from Antonio Martinez, was from San Ildefonso Pueblo and worked as part of the Special Engineering District at the Los Alamos Lab during the Manhattan Project.

The Laboratory's third director, Harold Agnew, recalled in a 1992 interview that, "I struck up in the very beginning a close acquaintance with, I called him Po, Tony Martinez, Popovi Da, who was Maria's son ... We just got along fine together and we would picnic together with [Harold Agnew's wife] Beverly and his wife, Anita, and our little kids. The first deer I ever shot was with Po and that really made us part of the family of the region."

The son of renowned potter Maria Martinez and an accomplished artist himself, Da focused on his pottery and worked closely with his mother after World War II ended.

He became a prominent potter, reviving the tradition of polychrome ware at San Ildefonso and experimenting with various other techniques. Da died in 1971 at age 48.

\section{Fred Begay}

caption: Los Alamos Physicist Fred Begay dedicated his life to science and leveraging his field to help Native American communities. The contributions of the Lab's early Native American staff members are preserved in the collections of the National Security Research Center, the Lab's classified library.

Fred Begay was the first member of the Navajo Nation to receive a Ph.D. in physics in 1972. 
Begay (Clever Fox), who changed his name from Frederick Young, was born in Colorado on the Ute Mountain Indian Reservation. His parents were Diné (the name for the Navajo people) and Ute.

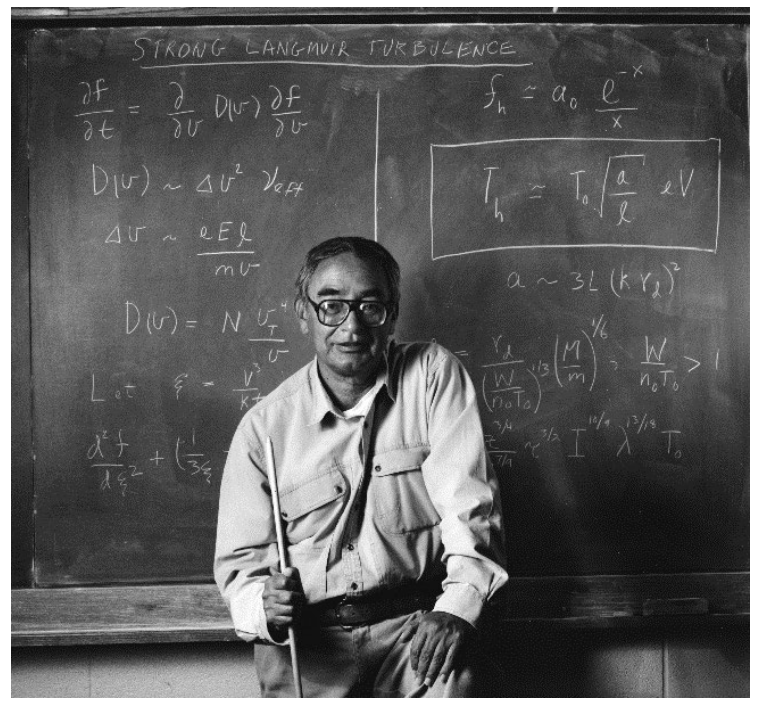

In 1951, Begay joined the U.S.Army to serve in the Korean War, and when he returned, he attended the University of New Mexico to study physics. After earning his Ph.D., Begay joined the Lab in the early '70s as a staff physicist and much of his work at Los Alamos was focused on laser research.

Begay was committed to helping the Navajo Nation and other Native American communities through his work as a scientist. In 1977, Begay, as chairman of the Navajo Science Committee, attended the Navajo Energy Conference. The conference was organized to help the Navajo Nation solve and discuss energy challenges, addressing both solar and geothermal energy.

After he retired from LANL in 2006, Begay served as the president of Seaborg Hall of Science, a nonprofit education and research institution. In this position, Begay was able to provide science-related services to the Navajo community. He died in 2013 at 80 years old.

Box:

November is Native American Heritage Month. Keep an eye out for other content from the Lab's American Indian Employee Resource Group (AIERG) and an original illustrated poster from the National Security Research Center (NSRC), the Lab's classified library. The NSRC's staff may be able to help you with your research. Contact us nsrc.lanl.gov.

more photos:

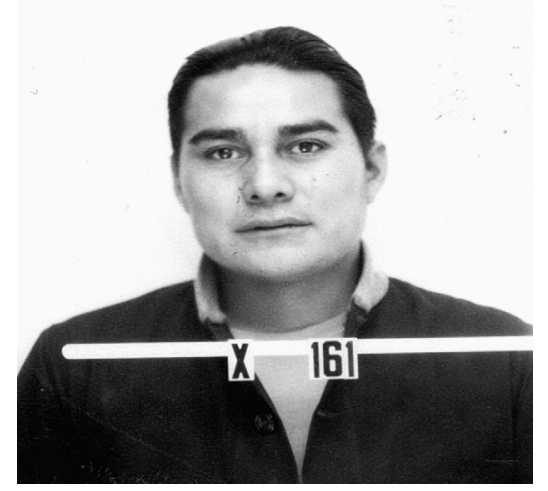

Popovi Da, pictured here in his Lab badge photo, worked as a machinist during World War II. 


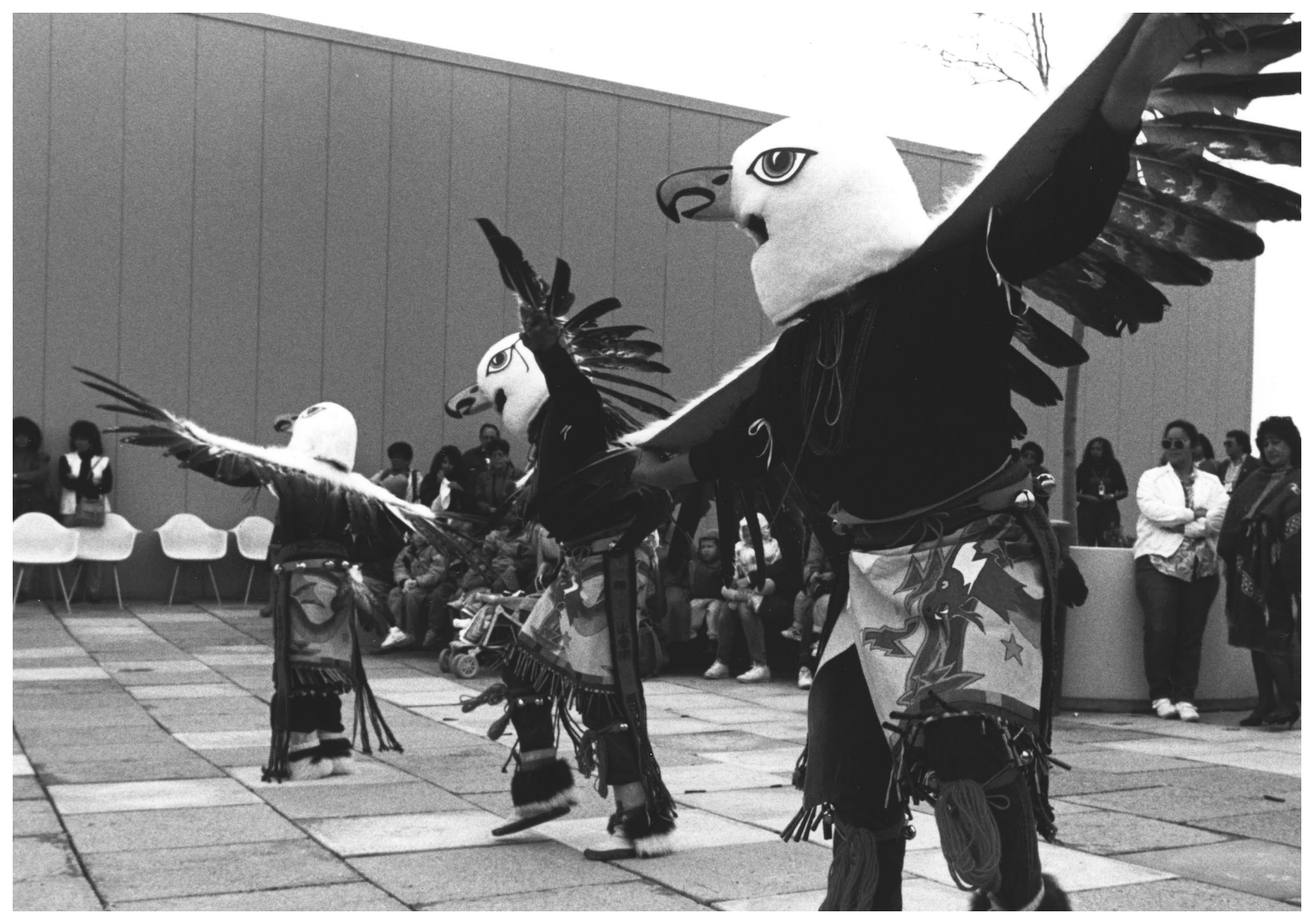

Native American communities were long-established when the lab in Los Alamos was built in 1943. In addition to hiring staff from surrounding pueblos, the Lab also benefited from the culture of Native Americans. 


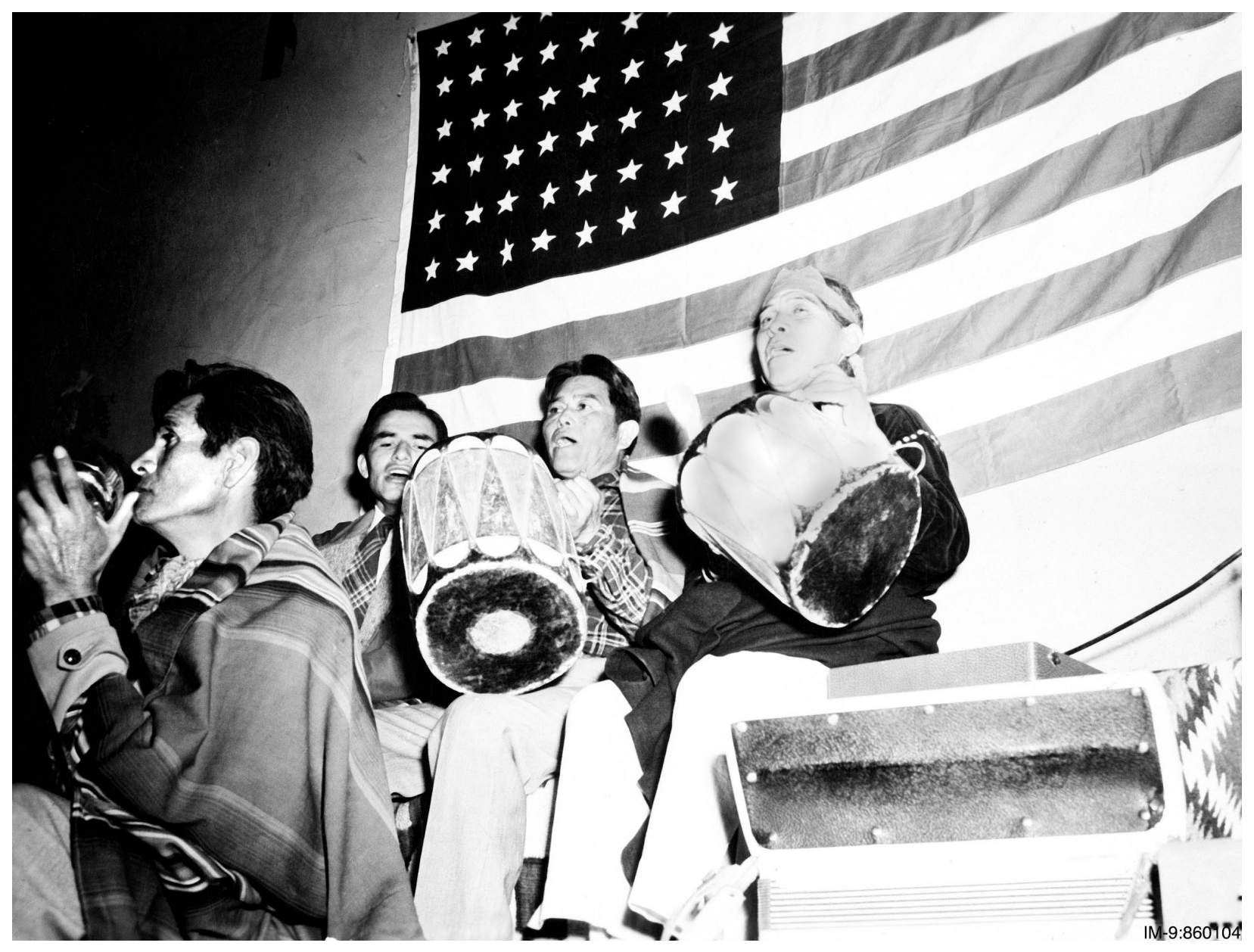

Native Americans joined the Lab's first workforce in the early 1940s, bringing with them their traditions such as music, as seen in this photo from the National Security Research Center -- the Lab's classified library. 